Document downloaded from:

http://hdl.handle.net/10251/58315

This paper must be cited as:

Hernández Hormazabal, JE.; Lyons, AC.; Poler, R.; Mula, J.; Goncalves, R. (2014). A reference architecture for the collaborative planning modelling process in multi-tier supply chain networks: a Zachman-based approach. Production Planning and Control. 25(1314):1118-1134. doi:10.1080/09537287.2013.808842.

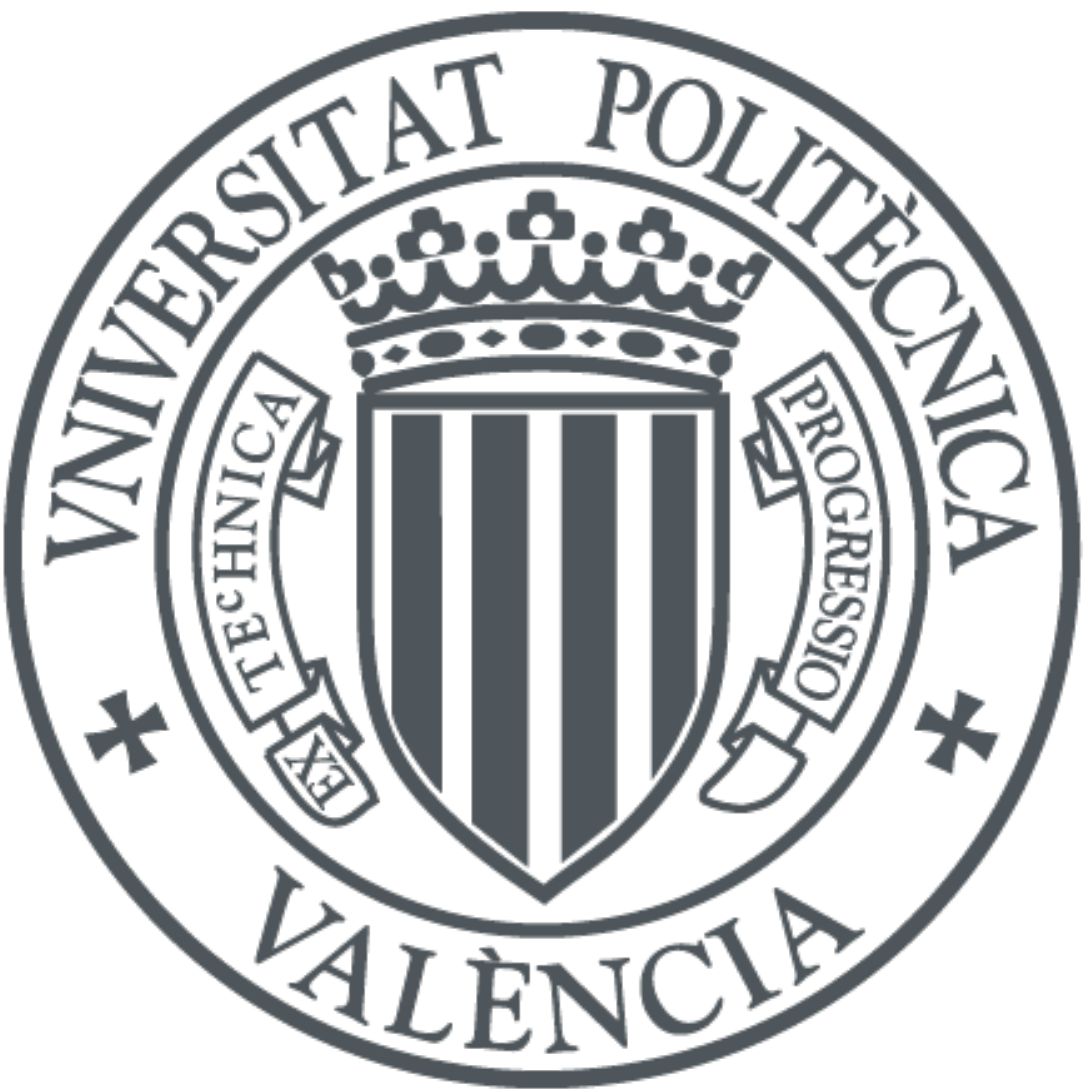

The final publication is available at

http://dx.doi.org/10.1080/09537287.2013.808842

Copyright Taylor \& Francis

Additional Information 


\title{
A reference architecture for the collaborative planning modelling process in multi-tier supply chain networks: A Zachman-based approach
}

\author{
Jorge E. Hernández§*, Andrew C. Lyons§, Raul Poler†, Josefa Mula†, \\ Ricardo Goncalvesф
}

$\S$ Management School, University of Liverpool, Liverpool, United Kingdom.

$\uparrow$ CIGIP (Research Centre on Production Management and Engineering), Universitat Politècnica de València, Valencia, Spain.

$\Phi$ CTS, Uninova, Dep. de Eng. Electrotécnica, Faculdade de Ciências e Tecnologia, FCT, Universidade Nova de Lisboa, Caparica, Portugal

*Address: Management School, University of Liverpool, Chatham Building, Chatham Street, L69 7ZH, Liverpool, UK. Tel. +44 (0)151 795 3608, Fax. +44 (0)151 795 3004. e-mail:

J.E.Hernandez@Liverpool.ac.uk

\begin{abstract}
A prominent and contemporary challenge for supply chain (SC) managers concerns the coordination of the efforts of the nodes of the SC in order to mitigate unpredictable market behaviour and satisfy variable customer demand. A productive response to this challenge is to share pertinent marketrelated information, on a timely basis, in order to effectively manage the decision-making associated with the SC production and transportation planning processes. This paper analyses the most well-known reference modelling languages and frameworks in the collaborative SC field and proposes a novel reference architecture, based upon the Zachman Framework (ZF), for supporting collaborative planning (CP) in multi-level, SC networks. The architecture is applied to an automotive supply chain configuration, where, under a collaborative and decentralised approach, improvements in the service levels for each node were observed. The architecture was shown to provide the base discipline for the organisation of the processes required to manage the $\mathrm{CP}$ activity.
\end{abstract}

Keywords: Collaborative planning, reference architectures, supply chain integration, automotive supply chain.

\section{Introduction}

From a tactical planning point of view, collaborative planning (CP) means that decision- 
making (DM) processes are supported by the exchange of demand plans in order, for example, to timely address and support material and capacity requirements' planning (Dudek and Stadtler, 2005). It is important to realise that DM processes can be explored from two perspectives. The first is the centralised perspective, where pertinent information is available to all nodes to support decision-making. On the other hand, the decentralised perspective requires that only specific information is shared between nodes. An example of this is presented by Hernández et al. (2011b), where a case study was undertaken in a collaborative automotive SC (CASC) to model and simulate the forward and reverse logistics processes. Relevant studies pertaining to this topic include those of Cutting-Decelle et al. (2007), who reviewed the main approaches for SC communication, Chan and Chan (2010), who set out a review of some recent studies related to SC coordination and Zeng et al. (2012), who analysed several research studies in this area.

We propose a reference architecture to support CP integration in multi-level SC networks using the physical-technology layer of the well-known and standardised Zachman's framework (Zachman, 1987). The main novelty of our proposal is that the objectives and constraints from the upper SC tiers to lower-tier suppliers are considered in addition to the related information exchange and agreement processes among the SC nodes. For this purpose, a range of reference frameworks and modelling languages were considered in order to provide suitable coverage for the $\mathrm{CP}$ and $\mathrm{DM}$ requirements in the SC.

This paper is organised as follows. Section 2 briefly reviews the literature on relevant modelling languages in SCs, collaboration in SCs and the use of standard frameworks and their applicability to support the collaboration and integration of SCs. 
Section 3, considering one particular layer from the Zachman's framework, presents the reference architecture and its key elements to support decentralised CP. Section 4, based on a real and representative automotive SC case study, provides an application of the reference architecture and the main managerial implications from this research. Finally, section 5 provides the main conclusions and suggestions for further research.

\section{Background}

\subsection{Standard modelling languages in supply chains}

In the SC context, one important factor to support the business modelling process is the definition or selection of the languages that are going to be used for describing the activities and processes. There is a diverse range of reference languages types for SC modelling, which can be classified as textual (Tx), code-oriented (Co) or visual (Vi) depending on the user interface and required development environment. Recker et al. (2009) developed a classification system for the modeling languages approach based on process modelling factors such as: illustration methods (Im), integrated techniques (Ite) and process description and execution (Pde). Table 1 reviews and presents, in alphabetical order, the most widely used modelling languages with a SC orientation, considering aspects such as: version (the latest version available till this research has been performed), characteristics (where relevant authors give an opinion of them) and type and approach to propose a classification of them from the aforementioned perspectives.

Table 1. Standard and reference modelling languages and their characteristics. 


\begin{tabular}{|c|c|c|c|c|}
\hline Name & Version & Characteristics & Type & Approach \\
\hline $\begin{array}{l}\text { Business Process Execution } \\
\text { Language }\end{array}$ & WS-BPEL 2.0 & $\begin{array}{l}\text { Specifies an executable process that } \\
\text { exchanges messages with other systems } \\
\text { (OASIS, 2007) }\end{array}$ & Vi & $\begin{array}{l}\text { Im } \\
\text { Ite }\end{array}$ \\
\hline $\begin{array}{l}\text { Business Process Modeling } \\
\text { Notation }\end{array}$ & BPMN 2.0 & $\begin{array}{l}\text { Language that defines a standardised way for } \\
\text { both the design of business processes and } \\
\text { their implementation (OMG, 2011) }\end{array}$ & Vi & $\begin{array}{l}\text { Im } \\
\text { Ite }\end{array}$ \\
\hline Data Flow Diagrams & DFD & $\begin{array}{l}\text { Depicts when, in what order and under what } \\
\text { conditions blocks are executed (Stevens et al. } \\
\text { 1974) }\end{array}$ & Vi & Im \\
\hline $\begin{array}{c}\text { Electronic Business using } \\
\text { eXtensible Markup } \\
\text { Language }\end{array}$ & ebXML 3.0 & $\begin{array}{l}\text { Open infrastructure that enables the global } \\
\text { use of business process information (Naujok } \\
\text { and Huemer, 2008) }\end{array}$ & $\begin{array}{l}\text { Tx } \\
\text { Co }\end{array}$ & $\begin{array}{l}\text { Ite } \\
\text { Pde }\end{array}$ \\
\hline Event-driven Process Chain & EPC & $\begin{array}{l}\text { Modelling language based on events that } \\
\text { identifies the system states and processes } \\
\text { (van der Aalst, 1999) }\end{array}$ & Co & Ite \\
\hline $\begin{array}{l}\text { Extensible Markup } \\
\text { Language } \\
\text { (XML) }\end{array}$ & XML 1.0 & $\begin{array}{l}\text { Code structure that allows reusing content in } \\
\text { various applications or environments (W3C, } \\
\text { 2008) }\end{array}$ & $\begin{array}{l}\text { Tx } \\
\text { Co }\end{array}$ & $\begin{array}{l}\text { Ite } \\
\text { Pde }\end{array}$ \\
\hline ICAM DEFinition & IDEFO & $\begin{array}{l}\text { Set of modelling languages for modelling, } \\
\text { simulation, object-oriented analysis and } \\
\text { design and acquisition of knowledge } \\
\text { (Colquhoun et al., 1993) }\end{array}$ & Vi & Ite \\
\hline PETRI NET & PN & $\begin{array}{l}\text { Visual language that represents the dynamics } \\
\text { of a system (Murata, 1989) }\end{array}$ & $\begin{array}{l}\mathrm{Vi} \\
\mathrm{Tx}\end{array}$ & Im \\
\hline Process Interchange Format & PIF 1.2 & $\begin{array}{l}\text { Language that support the exchange of } \\
\text { process descriptions among different process } \\
\text { representations (Lee et al. 1998) }\end{array}$ & $\begin{array}{l}\mathrm{Vi} \\
\mathrm{Co}\end{array}$ & $\begin{array}{l}\text { Im } \\
\text { Ite }\end{array}$ \\
\hline Role Activity Diagram & RAD & $\begin{array}{l}\text { Language oriented towards the people aspect } \\
\text { of a process in relation to the organisation } \\
\text { (Ould, 1995; Murdoch and McDermid, 2000) }\end{array}$ & Vi & $\mathrm{Im}$ \\
\hline $\begin{array}{l}\text { Unified Modelling Language } \\
\text { (UML) }\end{array}$ & UML 2.4.1 & $\begin{array}{l}\text { Support the modelling process from nine } \\
\text { standard perspectives in order to provide } \\
\text { different levels of detail from the system, } \\
\text { model or process (Scott, 2001) }\end{array}$ & $\begin{array}{l}\mathrm{Vi} \\
\mathrm{Co}\end{array}$ & $\begin{array}{l}\text { Im } \\
\text { Ite }\end{array}$ \\
\hline $\begin{array}{l}\text { XML Process Definition } \\
\text { Language (XPDL) }\end{array}$ & XPDL 2.2 & $\begin{array}{l}\text { Support the integration of graphics and } \\
\text { semantics from workflow business processes } \\
\text { (WFMC, 2008) }\end{array}$ & $\begin{array}{l}\text { Tx } \\
\text { Co }\end{array}$ & $\begin{array}{l}\text { Ite } \\
\text { Pde }\end{array}$ \\
\hline
\end{tabular}

From Table 1 it can be observed that modelling languages have evolved from visual and illustrated methods to code-oriented and integrated techniques. For a SC environment, in which entities, resources and information flows need to be represented to support the collaborative processes, the most suitable standard and reference modelling languages are BPMN, DFD, IDEF and UML. A useful analysis of these reference models can be found in Jardim-Goncalves et al. (2013). Nevertheless, important is to highlight that, because the dynamism of the environment, modelling languages evolves over the time as well, hence the proper study and selection of them will depend on the current industry necessities and modellers experience which will give less or more value to the selected reference modelling language. 


\subsection{Collaboration in supply chains to support the planning and decision-making process}

Collaboration arises from the agreements and trust mechanisms accepted and adopted by companies which belong to the SC. Hence, collaboration can be understood as the way in which nodes in a SC are actively working together and sharing information in order to achieve common objectives (Hernández et al., 2011b). In Moutaoukil et al. (2012), it has been established that, depending on the degree of commitment and involvement of partners, collaboration can range from simple information sharing to a true partnership, which may include cultural and organisational changes. In fact, what makes a forward SC successful is the collaboration, visibility, and trust of the various entities in the chain (Olorunniwo and $\mathrm{Li}, 2010)$. Information sharing among SC partners has become recognised as an important prerequisite for effective collaboration (Sandberg, 2007). Partners in collaborative companies can communicate and exchange information easily and cheaply using advanced collaborative technologies (Noordin et al., 2012). Nevertheless, the causal direction of: "information sharing results in collaboration" or "collaboration results in information sharing" is still subject to argument (Olorunniwo and Li, 2010).

In this $\mathrm{CP}$ context, the relationship between the information and decision flows is provided by considering existing process information to support the DM processes. In order to support the CP modelling process in a SC distributed decision-making context, Hernández et al. (2011a) presented a methodology implemented by multi-agent systems and enriched through mathematical programming models. In addition, the main collaborative mechanisms to support real implementations of the $\mathrm{CP}$ process in multilevel supply chains are addressed. The DM, in this case, was supported by the 
aggregation of information. However, justifying and demonstrating the benefits of collaborative solutions still remains a challenge and has been under-researched.

\subsection{Reference architectures and frameworks to support collaboration in supply chain networks}

Reference architectures and frameworks are well defined and organised structures that may be applicable to any type of environment. Reference frameworks consider a broad scope of elements such as tools, mechanisms, methods, resources, information, processes and flows to support the enterprise modelling process. Relevant architectures for information systems are reviewed by Bernus (2005), from which Chen et al. (2008) analyses the most significant approaches such as the Zachman Framework, ARIS, TOGAF, DoDAF, SCOR and many more, which can be utilised in any enterprise architecture.

To visualise this better, table 2 depicts and describes the principal features used by some authors who have used and applied reference frameworks to support the SC modelling processes of collaborative processes. Four dimensions are considered:

Domain (such as generic enterprises (GE), supply chains (SC), virtual enterprises (VE), web-based environments (WEB) and networks (NET)), Reference framework (used by authors to support the SC modelling process under a collaborative regime), main elements and reference modelling languages (such as business process management (BPM), communication (COM), collaboration (COL), customer service (CS), enterprise modelling perspective (EMP), integration (INT), ICT, human roles (HR) and knowledge management (KM)) and Reference modelling languages (to support the SC modelling process.

Table 2. Main reference model features, frameworks and modelling languages. 


\begin{tabular}{|c|c|c|c|c|}
\hline Author & Domain & $\begin{array}{l}\text { Reference } \\
\text { framework }\end{array}$ & $\begin{array}{l}\text { Main elements to support the } \\
\text { SC architecture }\end{array}$ & $\begin{array}{l}\text { Reference } \\
\text { modelling } \\
\text { language }\end{array}$ \\
\hline $\begin{array}{l}\text { Peristeras and } \\
\text { Tarabanis }(2000)\end{array}$ & GE & Generic & ICT, KM, HR & Generic \\
\hline $\begin{array}{l}\text { Ulieru et al. } \\
(2000)\end{array}$ & NET & Generic & BPM, COM, ICT & Agents \\
\hline Noran (2003) & GE & Zachman/GERAM & BPM, EMP & $\begin{array}{l}\text { UML } \\
\text { IDEFx }\end{array}$ \\
\hline Choi et al. (2005) & NET & Generic & BPM & $\begin{array}{l}\text { DFD } \\
\text { UML }\end{array}$ \\
\hline $\begin{array}{l}\text { Danilovic and } \\
\text { Winroth (2005) }\end{array}$ & NET & Generic & INT, ICT & Generic \\
\hline Liu et al. (2005) & $\mathrm{SC}$ & Generic & $\mathrm{COM}, \mathrm{CS}$ & $\begin{array}{l}\text { Workflow } \\
\text { Agents } \\
\text { XML }\end{array}$ \\
\hline $\begin{array}{l}\text { Rodriguez and } \\
\text { Al-Ashaab } \\
(2005)\end{array}$ & GE & CIMOSA & BPM, COM, COL, ICT & WEB \\
\hline $\begin{array}{l}\text { Simatupang and } \\
\text { Sridharan (2005) }\end{array}$ & $\mathrm{SC}$ & SCOR & BPM, INT & Generic \\
\hline Kim et al. (2006) & WEB & Generic & BPM, ICT & $\begin{array}{l}\text { JAVA } \\
\text { XML } \\
\end{array}$ \\
\hline $\begin{array}{l}\text { Spekman y } \\
\text { Carraway (2006) }\end{array}$ & NET & Generic & BPM, HR & Generic \\
\hline $\begin{array}{l}\text { Gruat La Forme } \\
\text { et al. (2007) }\end{array}$ & NET & Generic & BPM, COL, COM, BPM & UML \\
\hline Kua et al. (2007) & VE & Generic & BPM, EMP & $\begin{array}{l}\text { DFD } \\
\text { UML }\end{array}$ \\
\hline $\begin{array}{l}\text { Gutiérrez Vela et } \\
\text { al. (2007) }\end{array}$ & NET & Generic & HR & UML \\
\hline Choi et al. (2008) & $\mathrm{VE}$ & Zachaman/ FEAF & BPM, ICT & DFD \\
\hline $\begin{array}{l}\text { Hernández et al. } \\
\text { (2008) }\end{array}$ & GE & Generic & BPM, EMP, ITC, HR & DFD, IDEF0 \\
\hline $\begin{array}{l}\text { Romero et al. } \\
(2008)\end{array}$ & GE & Generic & BPM, COL, EMP, ICT & IDEF0 \\
\hline $\begin{array}{l}\text { Vries and } \\
\text { Rensburg (2008) }\end{array}$ & GE & Zachman & BPM, ICT & Generic \\
\hline Lee et al. (2009) & GE & Generic & BPM, EMP & Generic \\
\hline $\begin{array}{l}\text { Derrouiche et al. } \\
\text { (2010). }\end{array}$ & $\mathrm{SC}$ & Generic & FD & Generic \\
\hline $\begin{array}{l}\text { Berasategi et al. } \\
(2011)\end{array}$ & NET & Generic & FD & Generic \\
\hline Zapp et al (2012) & $\mathrm{SC}$ & SCOR/generic & BPM, INT & Generic \\
\hline $\begin{array}{l}\text { Hernández et al. } \\
\text { (2013) }\end{array}$ & $\mathrm{SC}$ & Zachman & COM, COL, EMP, INT, ICT & $\begin{array}{l}\text { Agents } \\
\text { DFD }\end{array}$ \\
\hline
\end{tabular}


Table 2 highlights that most authors adopt a general approach to define and support their architecture modelling processes This means that reference frameworks are being used to generalise the main SC processes. In addition to this, it is possible to note that the Zachman framework is the most-widely used and accepted by authors who want to address different views and perspectives of the SC modelling process. This is mainly attributable to its standards and robust characteristics.

From this brief review, it is noted that successful SC collaboration practices are rather exceptional, yet collaboration is believed to be the single most pressing need in SC management, and the ITC infrastructure is one of the reasons effective collaboration is difficult to achieve (Kampstra et al. 2006). In this paper, a reference architecture for supporting the integration and implementation of a $\mathrm{CP}$ model in a multi-level SC is proposed using the Zachman framework as a main structural base.

\section{A reference architecture for the collaborative planning integration in multi- level supply chains}

The proposed reference architecture aims to provide support to the collaborative production and replenishment planning in multi-level supply chains. Hence, the SC planning process is based on the conceptualisation of the product, information and decision flows established by Hernández et al. (2008) in their reference model for the conceptual modelling of the production planning processes (PPRM). In addition, the SC collaboration may involve many types of processes such as forecasting, planning, replenishment, inventory management, forward and reverse logistics.

The Zachman Framework (ZF), which has been widely accepted as a standard framework in the enterprise architecture community (Baïna et al. 2009), has been chosen to represent the main elements of the proposed reference architecture. For this 
$\mathrm{CP}$ application, the physical view from the $\mathrm{ZF}$ is considered to represent the main generic elements for the reference architecture proposal (RAR-CP).

In this section, by considering the inputs from PPRM (Hernández et al., 2008) for ZF level 1, SCAMM-CPA (Hernández et al, 2011a) for ZF levels 2 and 3, CPM (Hernández et al, 2011a) for ZF levels 3 and 5, and CASC (Hernández et al, 2011b; 2013) for ZF level 6, the technology-physical layer (see figure 1), also known as ZF level 4, was selected to provide the complete view of the main elements of RAR-CP (see section 4 for more details).

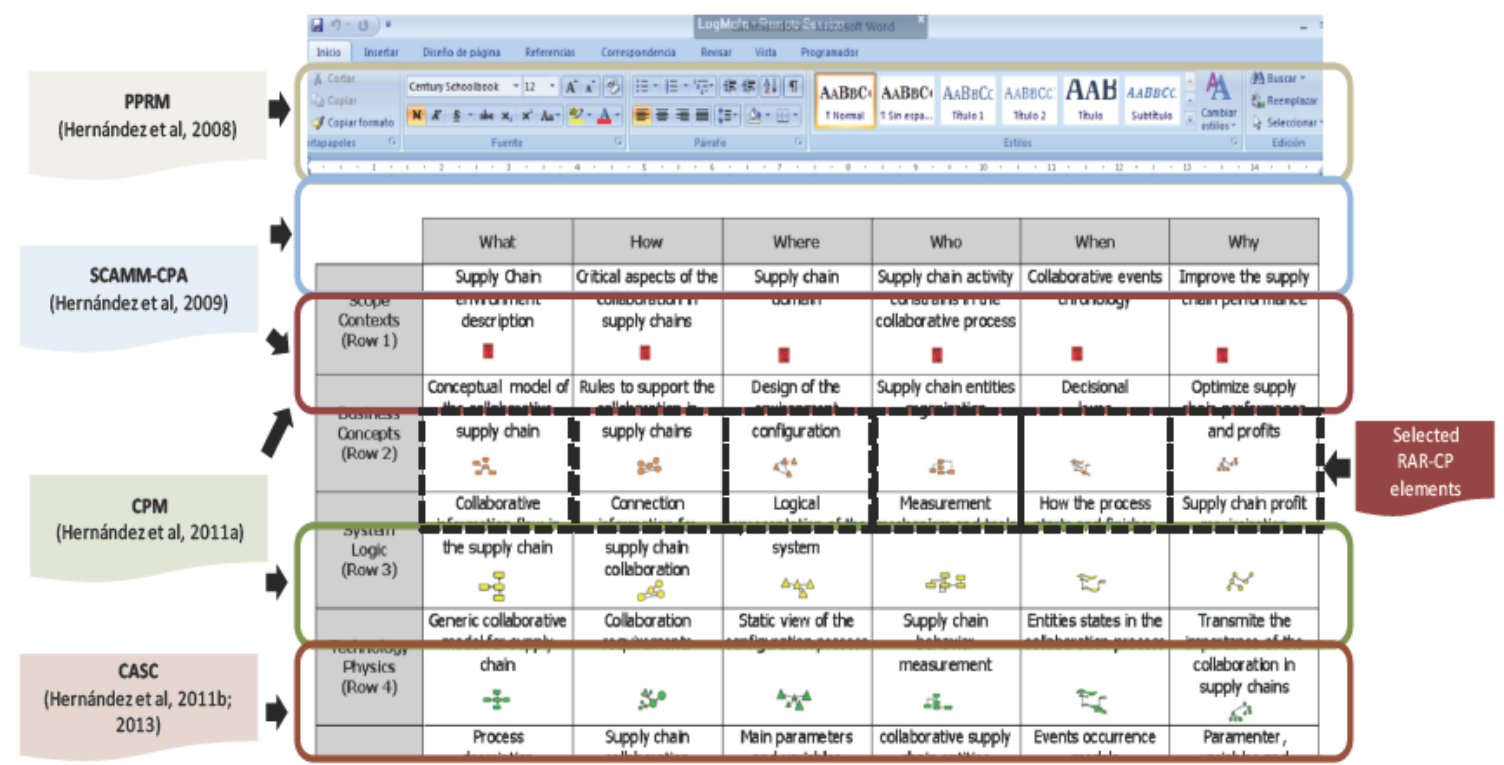

Figure 1. Building blocks for the collaborative SC integration. (adapted from the Zachman Framework (Zachman, 1997)).

The general purpose of RAR-CP is to provide support to the extended business processes between the SC nodes operating under a collaborative environment with the goal of achieving better DM performance in every node and in the whole SC. In particular, this paper is specifically focused on the CP process. This process is concerned with the exchange and negotiation of demand plans between the SC nodes and operates at a tactical DM level.

Considering and adapting to this case what is stated in the $\mathrm{ZF}$, the six selected dimensions to be considered concerns: Collaborative motivations (why), collaborative 
data model (what), requirements for collaboration (how), static view of the collaborative network (where), supply chain behavioural measurements (who) and entity states in the collaboration process (when) which are explained in Table 3.

Table 3. Reference architecture components and relationships for the Zachman technological perspective.

\begin{tabular}{|c|c|c|c|}
\hline Component & Description & Input & Output \\
\hline $\begin{array}{l}\text { Collaborative } \\
\text { motivations } \\
\text { (why) }\end{array}$ & $\begin{array}{l}\text { Describe and define the } \\
\text { requirements to support the } \\
\text { modelling and execution of } \\
\text { collaborative processes in } \\
\text { the SC. }\end{array}$ & $\begin{array}{l}\text { - Processes to become } \\
\text { collaborative. } \\
\text { - Constraints on behaviour. } \\
\text { - Modelling objectives. }\end{array}$ & $\begin{array}{c}\text {-Requirements to } \\
\text { support collaborative } \\
\text { processes. } \\
\text { - Objectives to be } \\
\text { achieved with the } \\
\text { collaborative behaviour. } \\
\text { - Requirements and } \\
\text { configuration data. }\end{array}$ \\
\hline $\begin{array}{l}\text { Collaborative } \\
\text { data model } \\
\text { (what) }\end{array}$ & $\begin{array}{l}\text { Identifies and characterises } \\
\text { the data requirements to } \\
\text { support the development of } \\
\text { collaborative processes in } \\
\text { the SC by considering the } \\
\text { flow of information among } \\
\text { SC nodes. }\end{array}$ & $\begin{array}{c}\text { - Requirements and } \\
\text { configurations of the data. } \\
\text { - Variables related to the states } \\
\text { of entities. } \\
\text { - Variables related to } \\
\text { behaviours }\end{array}$ & $\begin{array}{l}\text { - Data needs. } \\
\text { - Modelling parameters. }\end{array}$ \\
\hline $\begin{array}{l}\text { Requirements } \\
\text { for } \\
\text { collaboration } \\
\text { (how) }\end{array}$ & $\begin{array}{l}\text { Establishes the } \\
\text { requirements for the SC } \\
\text { configuration to support } \\
\text { the collaboration in the } \\
\text { SC. }\end{array}$ & $\begin{array}{l}\text { - Requirements to support the } \\
\text { collaboration in the SC. } \\
\text { - Behaviour constraints for } \\
\text { each node and the entire SC. }\end{array}$ & $\begin{array}{c}\text { - Guidelines, methods } \\
\text { and tools to support } \\
\text { collaboration. }\end{array}$ \\
\hline $\begin{array}{l}\text { Static view of } \\
\text { the } \\
\text { collaborative } \\
\text { network } \\
\text { (where) }\end{array}$ & $\begin{array}{l}\text { Sets out the representation } \\
\text { for the } \mathrm{SC} \text {. }\end{array}$ & $\begin{array}{l}\text { - Potential nodes of the SC. } \\
\text { - Nodes characteristics and } \\
\text { constraints. }\end{array}$ & $\begin{array}{l}\text { - SC physical } \\
\text { representation. } \\
\text { - SC informational } \\
\text { representation. } \\
\text { - Definition of entities. } \\
\text { - Configuration of } \\
\text { behaviours. }\end{array}$ \\
\hline $\begin{array}{l}\text { Supply chain } \\
\text { behaviours } \\
\text { (who) }\end{array}$ & $\begin{array}{l}\text { Block-oriented description } \\
\text { of the behaviours in the } \\
\text { SC. }\end{array}$ & $\begin{array}{l}\text { - SC settings. } \\
\text { - Modelling objectives. }\end{array}$ & $\begin{array}{c}\text { - Information flows to } \\
\text { define behavioural } \\
\text { states. }\end{array}$ \\
\hline $\begin{array}{l}\text { Entities states } \\
\text { in the } \\
\text { collaborative } \\
\text { process } \\
\text { (when) }\end{array}$ & $\begin{array}{l}\text { Identifies the states and } \\
\text { timing in which each node } \\
\text { can perform any process. }\end{array}$ & $\begin{array}{l}\text { - Information flows. } \\
\text { - Definition of the entities. } \\
\text { - Behaviour constraints for } \\
\text { nodes. }\end{array}$ & - State variables. \\
\hline
\end{tabular}

From table 3, it can be seen that the RAR-CP elements are mainly oriented to support the input and output specifications of the processes and to model the main definition for the collaborative SC. This is to be supported by the definition of the data, parameters, information flows, variables, requirements, constraints, entities and relationships. 


\subsection{Collaborative motivations (why)}

The selected technology-physical layer aims to collate the main requirements from the nodes in the SC by considering the individual and linked perspectives from an ICT point of view. The proposed RAR-CP is oriented to support a decentralised approach for defining a distributed collaboration across the SC. The main elements to support this ICT integration are: design (to define a scalable, maintainable and customisable architecture), implementation (to model the ICT components which support the collaborative information exchange across the SC levels) and support to the $\mathrm{CP}$ (to consider the main inputs, outputs and data processing according to the characteristics of every SC node).

In terms of the decentralised approach for the $\mathrm{CP}$, the generic approach is to define three types of entities, which also means identifying three types of behaviours. Firstly, those which consider only customer (C) functionalities; i.e., those which only send requests and wait for answers (offers) from their suppliers; secondly, those which consider only supplier (S) functionalities, where they wait for the orders from their customers and reply back with an answer; and finally, the nodes that contemplate both features $(\mathrm{C} / \mathrm{S})$; i.e., generate requests to suppliers and answers to customers. These nodes are meant to interact independently with their own information repositories (IR).

\subsection{Collaborative data model (what)}

This dimension is concerned with the data requirements definition. For this, the data IRs and the attributes of each SC have to be defined. It is also important to consider the inputs and outputs from every IR. These information relationships (table 4), are described by the following components: Elements (to define and describe the attributes 
that the main data will consider to support the CP process across the SC), Information repositories (to establish and classify the key information to be managed by the SC nodes in terms of transactions, i.e. demand (information requests from customers), answer (information feedback from suppliers), product tree (bill of materials), product master (detailed product information about lot-sizing, prices, quantities on hand or inventory and lead times), order (requests to the suppliers) and capacity (resources productive capacity)), and Nodes (to highlight which nodes from the SC are to be linked with the defined elements and tables).

Table 4. Elements, attributes, IRs and SC nodes relationships.

\begin{tabular}{|c|c|c|c|c|c|c|c|c|c|c|}
\hline \multicolumn{2}{|c|}{ Elements } & \multicolumn{6}{|c|}{ IR } & \multicolumn{3}{|c|}{ Node } \\
\hline Atributes & Description & Demand & Answer & $\begin{array}{c}\text { Product } \\
\text { Tree }\end{array}$ & $\begin{array}{c}\text { Product } \\
\text { master }\end{array}$ & Order & Capacity & $\mathrm{C}$ & $\mathrm{C} / \mathrm{S}$ & $\mathrm{S}$ \\
\hline Id & $\begin{array}{l}\text { Identifies the } \\
\text { specific node in } \\
\text { the SC }\end{array}$ & $\mathrm{X}$ & $\mathrm{X}$ & $\mathrm{X}$ & $X$ & $X$ & $X$ & $\mathrm{X}$ & $\mathrm{X}$ & $\mathrm{X}$ \\
\hline Periods & $\begin{array}{l}\text { Length of the } \\
\text { demand horizon }\end{array}$ & $\mathrm{X}$ & $\mathrm{X}$ & & & $\mathrm{X}$ & & $\mathrm{X}$ & $X$ & $\mathrm{X}$ \\
\hline DemandNx & $\begin{array}{l}\text { Node demand per } \\
\text { period }\end{array}$ & $\mathrm{X}$ & & & & & & $\mathrm{X}$ & $\mathrm{X}$ & \\
\hline AnswerNx & $\begin{array}{l}\text { Node answer } \\
\text { regarding a } \\
\text { particual demand }\end{array}$ & & $\mathrm{X}$ & & & & & & $\mathrm{X}$ & $\mathrm{X}$ \\
\hline Relationship & $\begin{array}{l}\text { Products and } \\
\text { components } \\
\text { relationship }\end{array}$ & & & $X$ & & & & $\mathrm{X}$ & $X$ & \\
\hline SP & $\begin{array}{l}\text { Product selling } \\
\text { price }\end{array}$ & & & & $X$ & & & $X$ & $\mathrm{X}$ & $\mathrm{X}$ \\
\hline BP & $\begin{array}{l}\text { Components } \\
\text { buying price }\end{array}$ & & & & $\mathrm{X}$ & & & $\mathrm{X}$ & $\mathrm{X}$ & \\
\hline OrdersNx & $\begin{array}{l}\text { Node net } \\
\text { requirements }\end{array}$ & & & & & $X$ & & $\mathrm{X}$ & $X$ & \\
\hline CapacityNx & Node capacity & & & & & & $\mathrm{X}$ & $X$ & $\mathrm{X}$ & $\mathrm{X}$ \\
\hline
\end{tabular}

Table 4 illustrates that $\mathrm{CP}$ in the $\mathrm{SC}$ is addressed by the information supported within $\mathrm{C}, \mathrm{C} / \mathrm{S}$ and $\mathrm{S}$ in terms of their demand, orders, SP, BP, capacities and answers. Thereafter, and considering the initial demand from the $\mathrm{C}$ nodes, RAR-CP establishes that the order information must be transmitted to the last node in order to promote the iterative $\mathrm{CP}$ process. Moreover, with this decentralised approach, each node aims to support and implement its own algorithm to calculate its costs, material needs and answers to the related nodes in the SC (see Figure 3). For a detailed example of these 
algorithms and calculations, we refer the reader to Hernández et al (2011a) and Mula et al (2010), respectively.

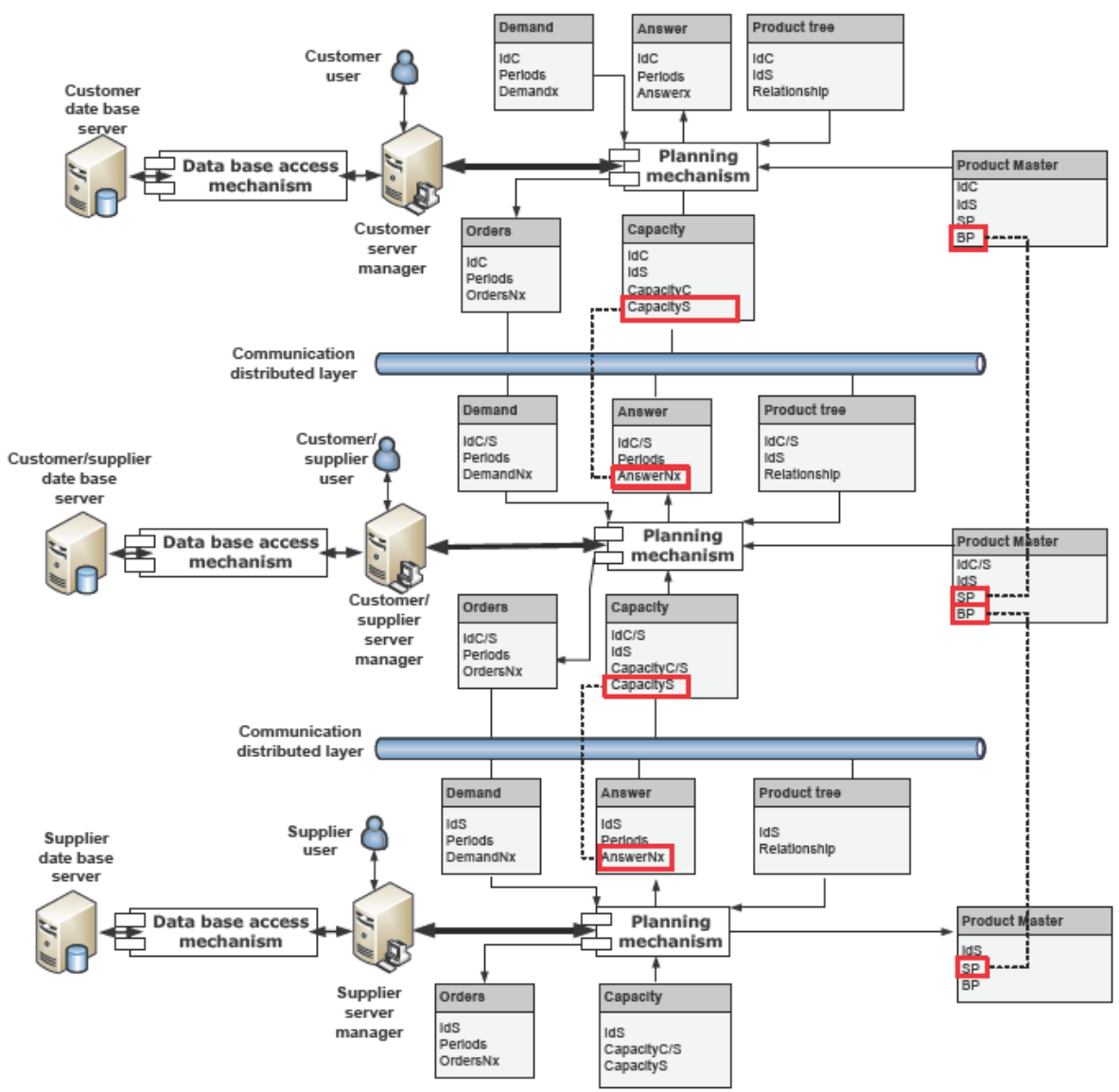

Figure 3. Data model to support CP in a multi-level SC.

From figure 3, every node generates and transmits its demand plan to every supplier node. From the information and data flow perspective this indicates that the proposed CP model aims to support the integration of information amongst the SC nodes. These concepts are subsequently considered by the RAR-CP model and its application.

\subsection{Requirements for collaboration (how)}

This model establishes the structure for supporting the communication process amongst the SC nodes. The model identifies the main requests, responses, proposals and evaluations which are to promote agreements and improvements in the SC. The ICT 
perspective uses standards or reference communication protocols, such as the FIPAACL (FIPA, 2013) messaging protocols, which support the information exchange between nodes (Figure 4). The CP perspective establishes the message structure by defining the sender, receiver and content.
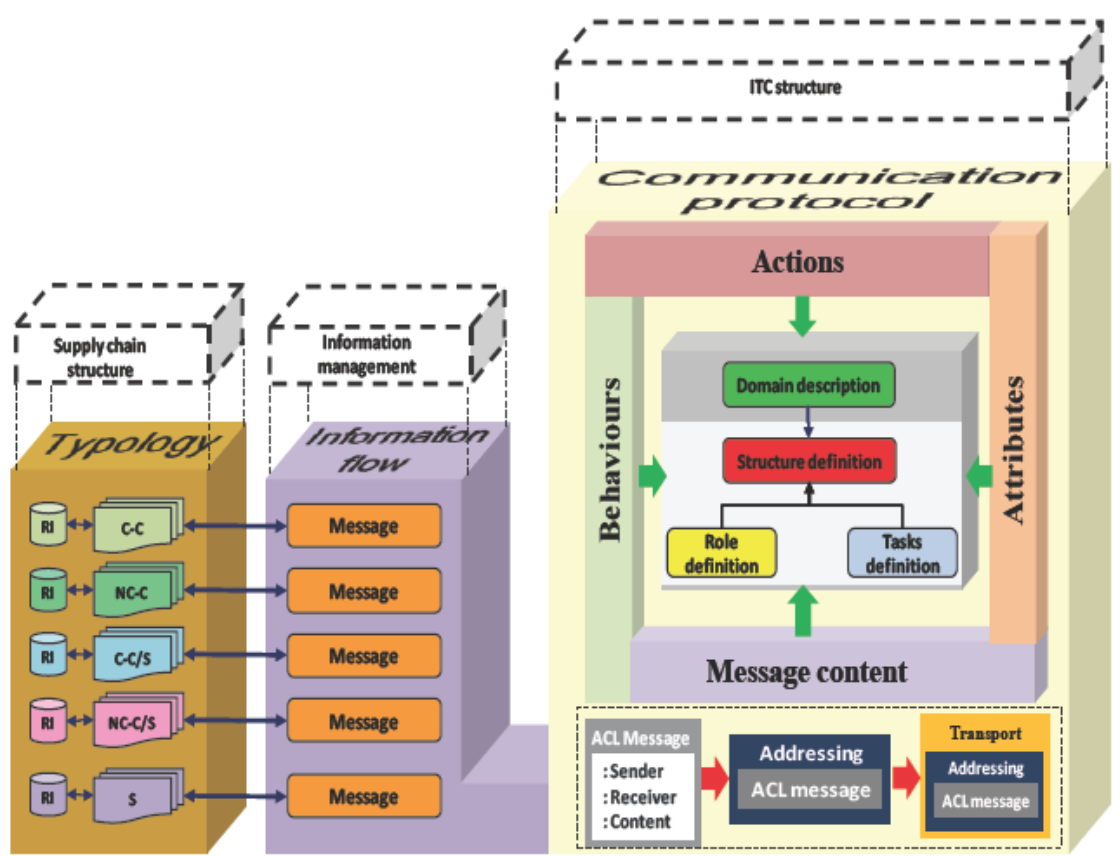

Figure 4. ICT structure and elements to support the collaborative information flow in SCs. The collaborative model regards the information flow to be unidirectional and independent of every node across the SC. From this perspective, the RAR-CP considers: IRs for each node, the information exchange, the structure of the main components (typology, flow and communication layer) and the specific roles and tasks to support the collaboration domain in the SC.

\subsection{Static view of the collaborative network (where)}

The static models will represent and describe the structure of the domain in a specific time or instance. A combination of DFD and UML is used to support this view (see Figure 5). Different types of domains can be addressed by considering the information flow distribution, such as vertical (V) or horizontal (H), and the SC node configurations 
(see table 5). The objective of this dimension, considering what has been established by Hoberman (2009), is to obtain a more flexible and stable representation that will be as reliable as possible $\mathrm{n}$ real environments.

Table 5. Example of SC configurations characteristics

\begin{tabular}{|c|c|c|c|c|}
\hline Representation & Name & Information flow & Levels & Complexity \\
\hline & Dyadic & $\mathrm{V}$ & $\leq 2$ & Low \\
\hline & Wheel & $\mathrm{V} / \mathrm{H}$ & $\leq 2$ & High \\
\hline & Sequence & $\mathrm{V}$ & $>=2$ & Medium \\
\hline
\end{tabular}

The configuration will move from low complexity in terms of levels and information, to high complexity. The data model that supports this dimension considers four principal views: conceptual and logical, SC typology, physical and information systems (see figure 5).

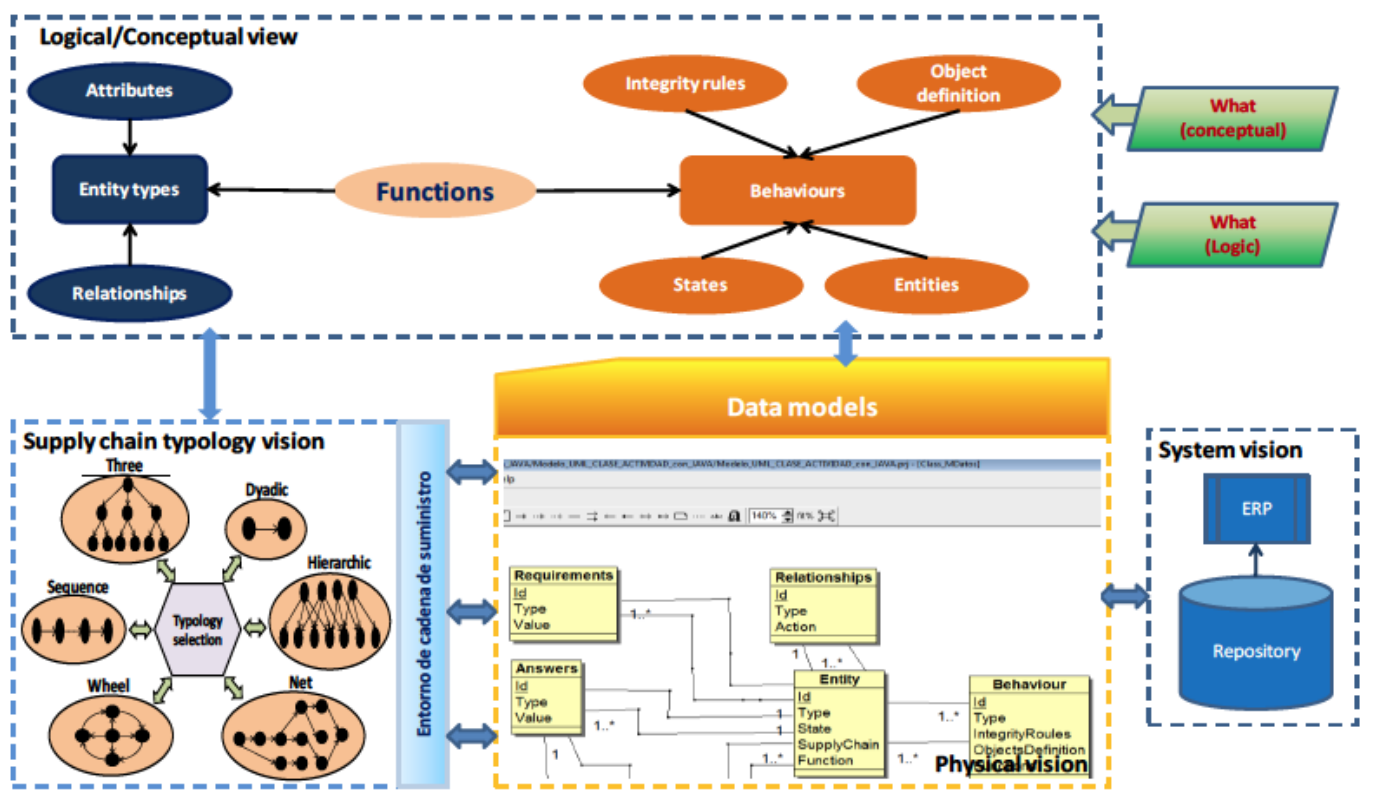

Figure 5. Elements and relationships for the static model in SCs.

With regard to the behaviours addressed in figure 5, the SC nodes consider a collaborative or a non-collaborative approach in addition to their possible $\mathrm{C}, \mathrm{C} / \mathrm{S}$ and $\mathrm{S}$ 
behaviour types. The main information flows, considering the legacy from the data and collaborative models will be represented by: requirements, responses, proposal assessments and new proposals generated. These will be accessed by the enterprise applications such as an enterprise resource planning (ERP) system which is linked with the RI. The information flows within this dimension in the RAR-CP address the physical and technological views of the $\mathrm{CP}$ in the $\mathrm{SC}$ by using standard object notations to establish the links across the SC and the CP among the SC nodes. These links concern concepts such as entities, behaviours, relationships, requirements, responses and messages.

\subsection{Supply chain behaviours (who)}

Behaviours are based on the previously defined generic categories for every node $(\mathrm{C}$, $\mathrm{C} / \mathrm{S}$ and $\mathrm{S}$ ), in which behaviours is characterised by its activities which leads to its own $\mathrm{CP}$ decision-making process. One key characteristic concerns the suppliers. They acts as responders to the different requests that they receive, which means their status is to support the collaborative mechanisms from top levels by receiving new proposals from their collaborative customers, or for example, by receiving new proposals and responding to them with an accurate answer. The information flow which links the mechanisms between nodes across the SC under a collaborative perspective is presented in figure 6 by using the reference modelling language BPMN (OMG, 2011). 


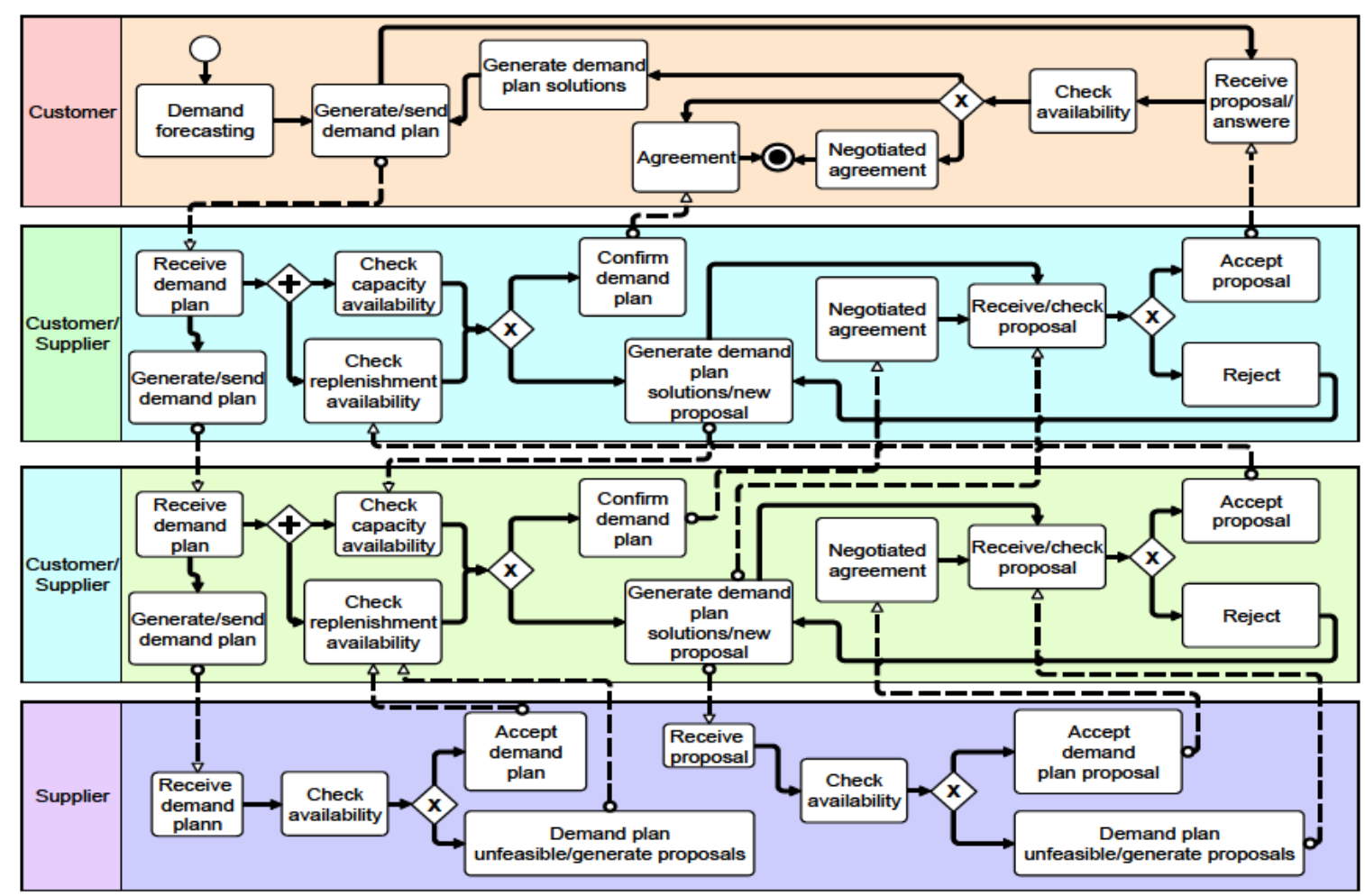

Figure 6. The CP behaviour in multi-level SC based on a BPMN model.

In addition, the $\mathrm{CP}$ approach for this dimension supports a vertical and horizontal information exchange. The vertical approach relates to the information flows between different levels of the SC, for example, between client nodes, client / vendor or supplier, and the horizontal approach concerns the collaboration for the information exchange that exists at the same level of the SC. This flow is related to the different SC typologies.

\subsection{Entities states in the collaborative process (when)}

The state model, beyond addressing only the state linked to every type of behaviour, highlights how these states are linked to each other. This is represented by an activity diagram based on the UML standard (figure 7). We consider the information enriched with the limitations of suppliers to respond to the respective customers in which each node has its own RI which, through the use of ontologies and communication standards, 
favours the independent collaborative execution of the CP mechanisms in the SC.

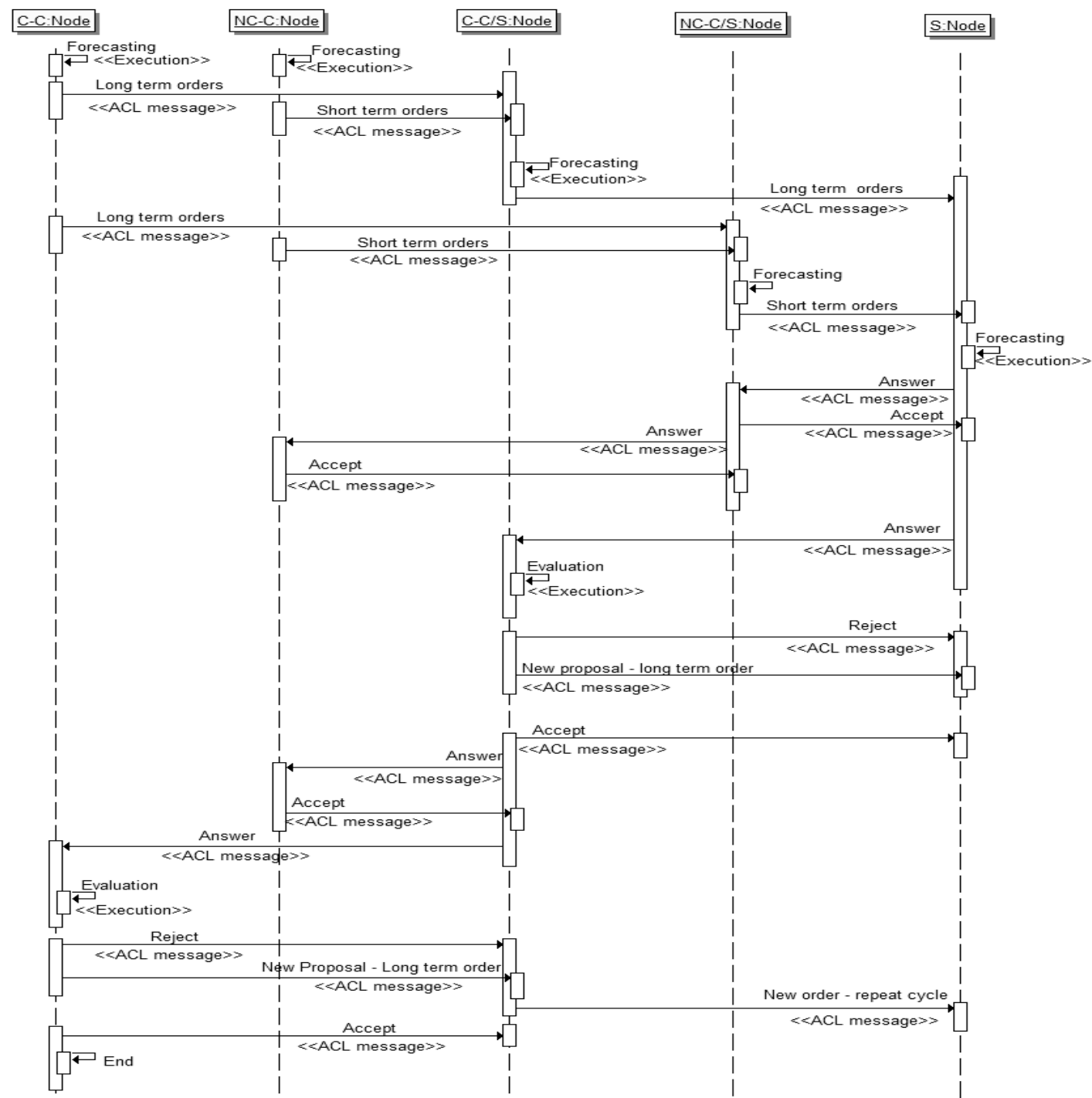

Figure 7. SC entity states to support the $\mathrm{CP}$ in $\mathrm{SC}$ within a UML activity model.

Nodes establish collaborative relationships by sharing information with their respective customer nodes to support CP. Suppliers' nodes are able to anticipate future order problems with regard to the distortion of demand and then, send back improved information with the requirements for their own customers and suppliers. On the other hand, if the node type $\mathrm{C}$ or $\mathrm{C} / \mathrm{S}$ sends information concerning a short-term horizon, a non-collaborative behaviour can be addressed. 


\section{Application of RAR-CP to the automotive supply chain sector}

Here, a model to support CP in a multi-level SC is implemented and evaluated, specifically, where: PPRM is considered to support the main conceptual rules for the selected SC domain specification (level 1); SCAMM-CPA is used to support the modelling methodology for the CP process in SCs using multi-agent systems (levels 2 and 3) in order to provide a formal view of the information exchange process; CPM supports the $\mathrm{CP}$ mechanism implementation by defining the main inputs required to support the DM across the SC (levels 3 and 5) and finally, the selected SC description is covered by CASC (level 6). From this, level 4 generates the specific RAR-CP components that will support the $\mathrm{CP}$ in this $\mathrm{SC}$ and level 6, considering the previous works from Hernández et al. (2011a; 2013) as good multi-agent system (MAS) implementation examples, is extended by using the MAS technology to support the application of RAR-CP and the evaluation of the results. The analysed SC belongs to the automotive sector and can be seen as a sequenced SC arrangement, in which sequences of activities are linked to the assembly of seats.

In this domain, the information sharing process implies achieving a more suitable and better DM process in each of the SC tiers. This is predicated on the notion that each DM process in the SC undertakes a negotiation activity to generate better information and create an advantage. The proposed model concerns node 1: automobile manufacturer (customer or C); node 2: first-tier suppliers (manufacturer or $\mathrm{C} / \mathrm{S}$ ) and node 3: second-tier suppliers (supplier or S).

\subsection{The multi-agent based model for RAR-CP}

A MAS approach was conceived to support the implementation of the RAR-CP in the 
automotive SC case study. Here, MAS are used because of their characteristics for providing a common platform for the ICT exchange in a SC collaboration context. One of the major benefits in using MAS, as established by Al-Mutawah et al. (2009), is that the effort of decision-making is devolved to potential agents so that each agent provides a reply to a request based on its own operational constraints. Another example has been provided by Marques and Guerrini (2012), who used the agent-based analytical innovation network approach to propose a reference model based on the enterprise knowledge development (EKD) to implement MRP in a lean production environment

For this RAR-CP application, the MAS model not only represents each node, but also the information sharing process between the nodes. Despite the complexity of the configuration, the MAS model can be applied straightforwardly to support the CP process (see figure 8). The principal aim of the MAS-based model is to promote the end-customer demand fulfilment.

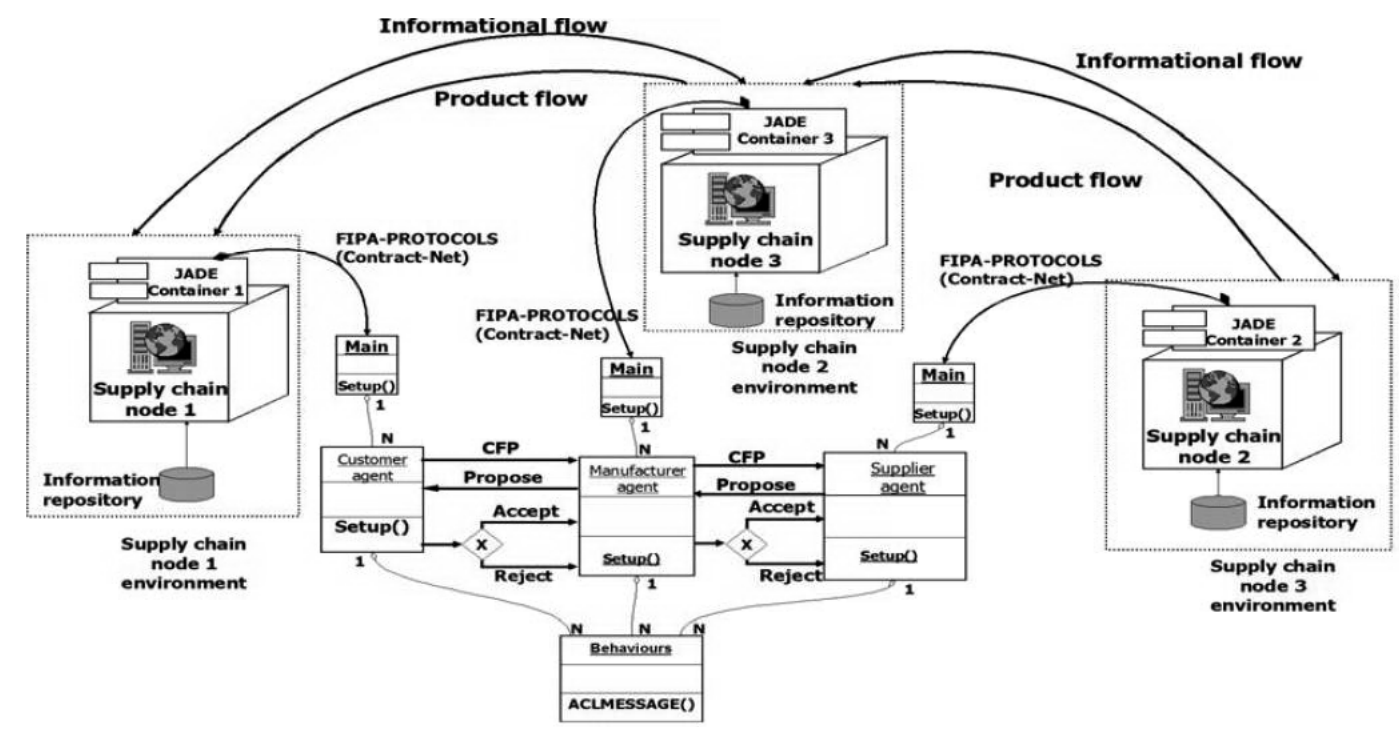

Figure 8. MAS-based model for the CP in the SC (adapted from Hernández et al. 2013).

As Figure 8 illustrates, the model for the CP process adopts a technical viewpoint oriented to define different IRs in order to share information. Hence, this architecture is MAS-based and designed to handle either collaborative (COLL) or non- 
collaborative (NCOLL) answers, which will provide the support to execute the multilevel and iterative negotiations' mechanisms in every node, independently.

\subsection{CP model implementation}

By moving from the traditional to the COLL approach in this $\mathrm{SC}$, the $\mathrm{CP}$ process adopts a negotiation process to generate a better collaborative decision-making mechanism (CDM). Then, by adapting the generic definition from the MAS architecture (figure 8), the implementation of the MAS in the automotive case study is presented in figure 9. The main DM information is collected in the IR or databases (DB) and then used by the CDM mechanism in order to support the decentralised CP process as stated in section 3 .

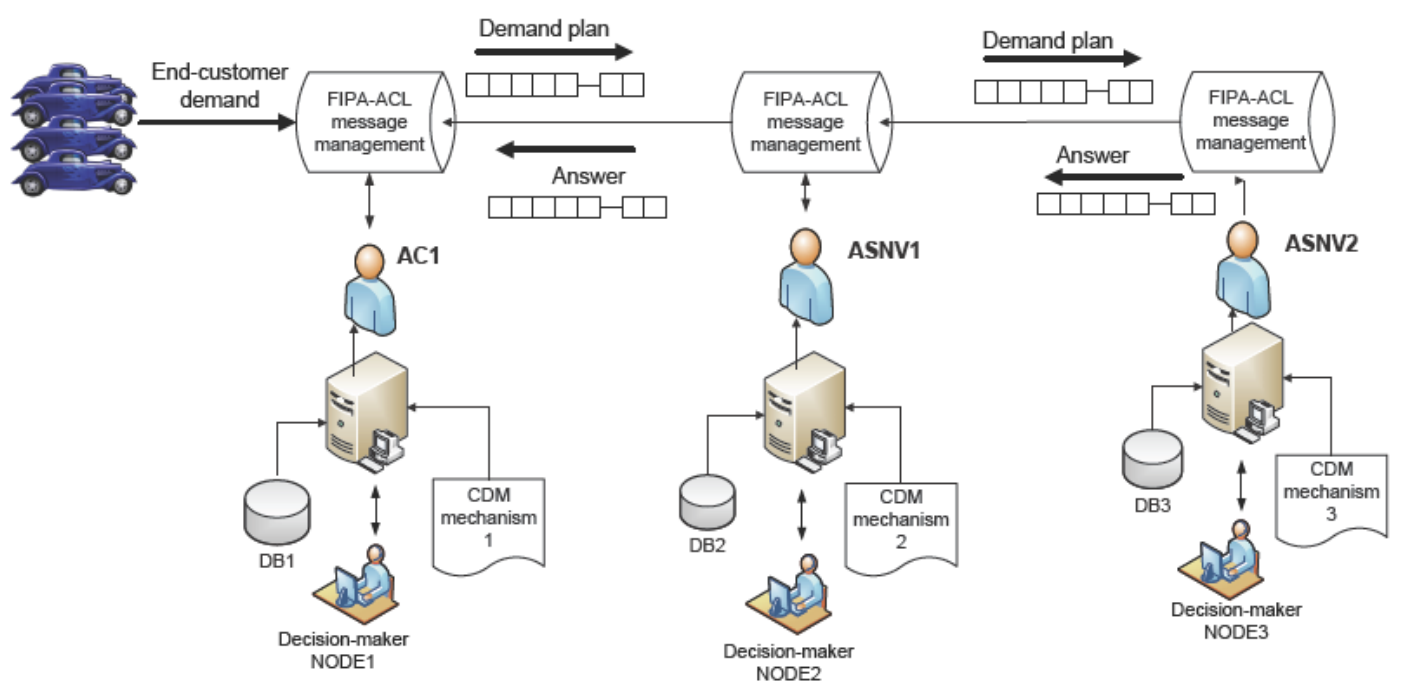

Figure 9. Application of the MAS to an automotive SC considering the reference architecture

With regard to the demand pattern from the end-customer or automotive manufacturer, there is a bi-directional informational flow between the agents. As can be seen in figure 9, the demand flows from the end-customer to the bottom by generating either COLL or NCOLL answers. For the validation purpose of this MAS-based model, one characteristic product has been considered as well as its characteristic demand, which considers a variability of $25 \%$ due to the manufacturing uncertainties. The analysis of this representative product allows us to generalise its behaviour to any item 
in the system. It is important to highlight that the MAS-based model will not only generate a solution for every node, but also for the global perspective of the SC. Thereafter, to demonstrate the applicability and efficacy of this proposed model, by considering a base workload of 100 (which means full capacity), a comparative analysis was undertaken in terms of measuring the difference DIF between the NCOLL and COLL approaches (see table 6) by considering different ranks of work-loads in order to realise the impact of the service level for every node and the whole SC.

Table 6. SC service level analysis.

\begin{tabular}{|c|c|c|c|c|c|}
\hline \multirow{2}{*}{ Workload } & \multirow{2}{*}{$\begin{array}{c}\text { Supply } \\
\text { chain } \\
\text { level }\end{array}$} & \multirow{2}{*}{ Agent } & \multicolumn{3}{|c|}{ Demand variability - $25 \%$} \\
\hline & & & NCOLL & COL & $\begin{array}{c}\text { DIF } \\
\text { (COLL-NCOLL) }\end{array}$ \\
\hline \multirow{4}{*}{90} & 1 & $\mathrm{AC} 1$ & $9987 \%$ & $9995 \%$ & $008 \%$ \\
\hline & 2 & ASNV1 & $9985 \%$ & $9995 \%$ & $009 \%$ \\
\hline & 3 & ASNV2 & $9992 \%$ & 99 96\% & $004 \%$ \\
\hline & SC & & $99.87 \%$ & $99.95 \%$ & $0.08 \%$ \\
\hline \multirow{4}{*}{100} & 1 & $\mathrm{AC} 1$ & $9754 \%$ & $9979 \%$ & $225 \%$ \\
\hline & 2 & ASNV1 & $9692 \%$ & $9980 \%$ & $288 \%$ \\
\hline & 3 & ASNV2 & $9717 \%$ & $9981 \%$ & $264 \%$ \\
\hline & SC & & $97.54 \%$ & $99.79 \%$ & $2.25 \%$ \\
\hline \multirow{4}{*}{110} & 1 & $\mathrm{AC} 1$ & $9970 \%$ & $9989 \%$ & $019 \%$ \\
\hline & 2 & ASNV1 & $9965 \%$ & $9989 \%$ & $024 \%$ \\
\hline & 3 & ASNV2 & $9971 \%$ & $9989 \%$ & $018 \%$ \\
\hline & SC & & $99.70 \%$ & $99.89 \%$ & $0.19 \%$ \\
\hline
\end{tabular}

From table 6, DIF (COLL-NCOLL), it is possible to observe that at the workload level of 100 the CP MAS-based model provides larger service level improvements than the other workload levels. Secondly, at the workload level of 110, the CP MAS-based model tends to provide better solutions than the workload level 90. This implies the CP MAS-based model behaves better the more occurrences of disruptions in demand.

\subsection{Managerial implications from the application of $R A R-C P$}

The RAR-CP proposal, based on the ZF, is oriented to support the modelling process 
and its implementation of different elements. The inputs and outputs from each block are interrelated with others at the same level or at different levels in the SC. As shown in figure 10 , models and components are developed by considering a holistic and integrated view. This integrated view must consider concepts and elements such as data, structure, entities and behaviours.

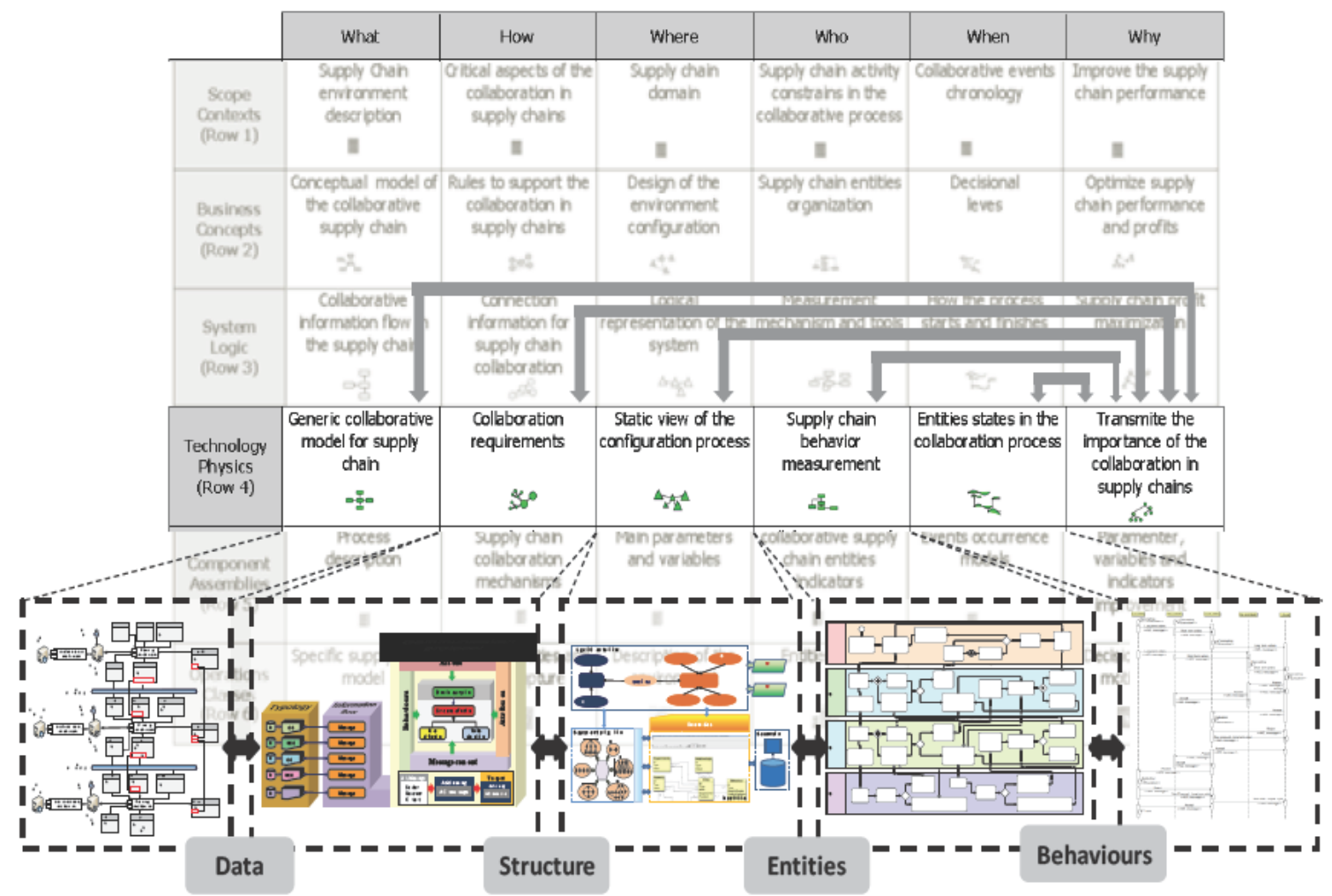

Figure 10. The reference architecture to support the CP integration in multi-level SC networks.

It is worth stressing that the six views also establish requirements, foundations and lines of action to develop the business process models at every layer of detail. The study about the modelling domain in a SC can be done to support the planning process in terms of information collection, and for the generation and distribution of the associated demand plans. Thus, the study of this type of collaborative issue inevitably implies considering the SC typologies, as well as the entities related with its business processes, for example: internal entities, additional internal entities, external entities and distribution centres. Similarly, studying and defining the concepts that support the 
domain description in accordance with the related products, information and decision flows, and identifying the modelling tools that address conceptual model building, can be considered by different layers of the proposed reference architecture (see figure 11).

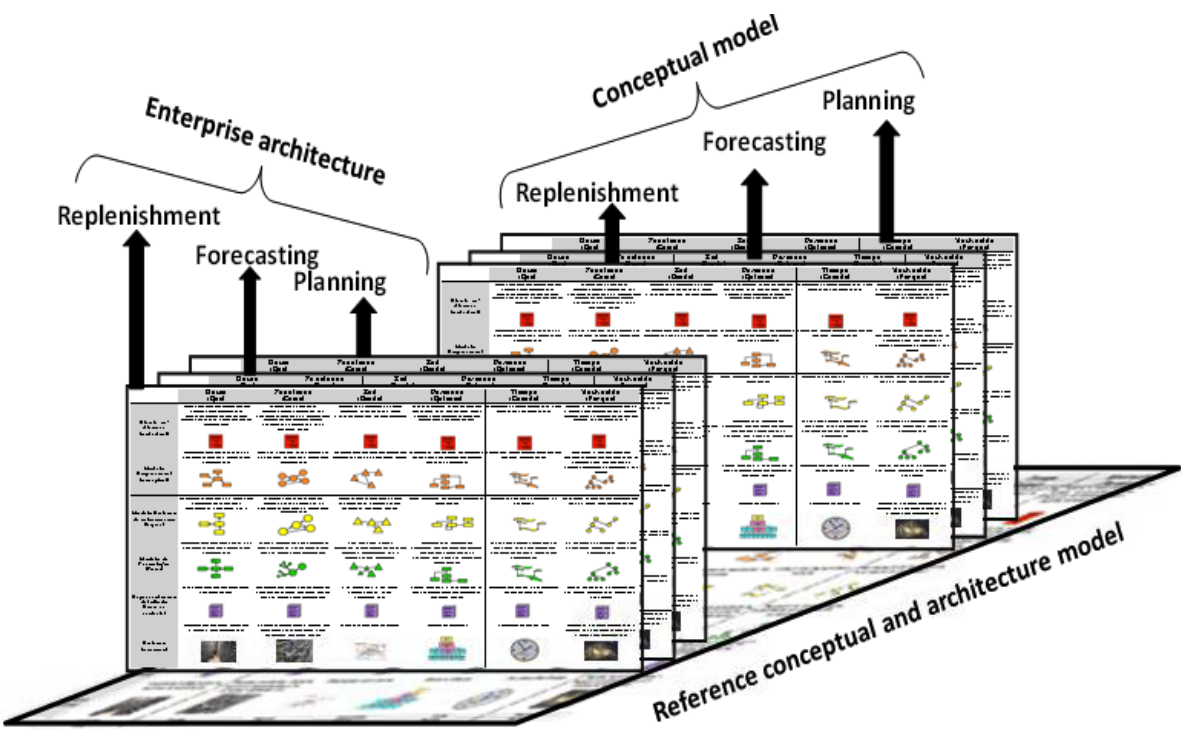

Figure 11. Proposed reference architecture model extensions.

From figure 11 it is possible to define the links between the information flow, architecture elements, perspectives and the SC typology. The product flow interacts with the information flow by means of interfaces which allow users to filter their requirements and information they are supplied with. With regard to the connection between product flow and decision flow, the link is established by the requirements that must be met, for which, and depending on information obtained from the process, the corresponding decisions will be made.

\section{Conclusions}

This paper has presented a novel reference architecture proposal based on reference frameworks, models and modelling languages to support CP in SCs. In addition, this reference architecture model is oriented to integrate the collaborative planning in multilevel SCs. Specifically, for the modelling and implementation purposes, this proposal 
has utilised the physical-technology layer from the Zachman enterprise framework in order to provide a well-defined structure to the architecture. To undertake this, definitions and concepts relating to the models by using reference and standard approaches within different characteristics have been considered. It is important to point out that to construct or devise a model of any kind, it is necessary to establish the order in which it is to be built. This order is directed to establish communication with the firm's entities and to capture its interests and needs. Studying the already existing documentation in the firm is also considered, as is the generation of new documentation that acts as a means of communication between the users and the work team members. The reference architecture has been used in a real case study in the automotive sector and the main managerial implication has been provided for supporting further implementations and applications. The structure and definition of this SC domain provided the opportunity to realise how the proposed reference architecture should be implemented.

Furthermore, it is possible to conclude that multi-agent systems are an appropriate tool to model collaborative processes where the information emanating from the collaborative and non-collaborative SC nodes must be identified. For further research it is expected to: (1) apply this architecture to study the collaboration in SCs with another approach such as mathematical modelling or discrete event-based simulation, (2) apply other semantics and ontologies to this architecture and, (3) consider other reference frameworks such as SCOR in order to compare its applicability to other real SC networks. 


\section{Acknowledgements}

The authors thanks the support from the project 'Operations Design and Management in Global Supply Chains (GLOBOP)' (Ref. DPI2012-38061-C02-01), funded by the Ministry of Science and Education of Spain, for the supply chain environment research contribution.

\section{References}

Al-Mutawah, K., Lee, V. and Cheung, Y., 2009. A new multi-agent system framework for tacit knowledge management in manufacturing supply chains. Journal of Intelligent Manufacturing, 29 (5), 593-610.

AMICE Esprit Consortium, 1993. CIMOSA: Open System Architecture for CIM. SpringerVerlag.

Arkin, A. and Intalio, 2002. Business process modeling language. Available at: http://xml.coverpages.org/BPML-2002.pdf (Accessed on 02/01/2013).

Berasategi, L., Arana, J. and Castellano, E., 2011. A comprehensive framework for collaborative networked innovation. Production Planning and Control, 22 (5-6), 581593.

Baïna, S., Panetto, H. and Morel, G., 2009. New paradigms for a product oriented modelling: Case study for traceability. Computers in Industry, 60 (3), 172-183.

Bernus, P. 2005. Handbook on architectures of information systems. Springer.

Chan, H.K. and Chan, F.T.S., 2010. A review of coordination studies in the context of supply chain dynamics. International Journal of Production Research, 48(10), 2793-2819.

Chen, D., Doumeingts, G. and Vernadat, F., 2008. Architectures for enterprise integration and interoperability: Past, present and future. Computers in Industry, 59, 647-659.

Choi, Y., Kim, K. and Kim, C., 2005. A design chain collaboration framework using reference models. International Journal of Advanced Manufacturing Technology, 26, 183-190.

Choi, Y., Kang, D., Chae, H. and Kim, K., 2008. An enterprise architecture framework for collaboration of virtual enterprise chains. International Journal of Advances manufacturing and technology, 35, 1065-1078.

Colquhoun, G.J, Baines, R.W. and Crossley, R., 1993. A state of the art review of IDEF0. International Journal of Computer Integrated Manufacturing, 6 (4), 252-264.

Cutting-Decelle, A.F., Young, B.I, Das, B.P., Case, K, Rahimifard. S, Anumba, C.J. and Bouchlaghem, D.M, 2007. A review of approaches to supply chain communications: from manufacturing to construction, ITcon Vol. 12, pg. 73-102. Available at: http://www.itcon.org/2007/5 (Accessed on 01/07/2012)

Danilovic, M. and Winroth, M., 2005. A tentative Framework for analyzing integration in collaborative manufacturing network settings: a case study. Journal of Engineering and Technology Management, 22, 141-158. 
Derrouiche, R., Neubert, G., Bouras, A. and Savino, M., 2010. B2B relationship management: A framework to explore the impact of collaboration. Production Planning and Control, $21(6), 528-546$.

Dudek, G. and Stadtler, H., 2005. Negotiation-based collaborative planning between supply chains partners. European Journal of Operational Research, 2005; 163 (3), 668-687.

ECMA, 1966. Standard ECMA 4: Flowcharts. European Computers Manufacturers Association.

FIPA, 2013. The Foundation for Intelligent Physical Agents (FIPA). Available on: http://www.fipa.org/ (accessed on 26/01/2013).

Gruat La Forme, F.A, Genoulaz, V.B. and Campagne, J.P. (2007) A framework to analyse collaborative performance. Computers in Industry, 58 (2007) 687-697.

Gutiérrez Vela, F.L., Isla Montes, J.L., Paderewski Rodríguez, P., Sánchez Román, M. and Jiménez Valverde, B., 2007, An architecture for access control management in collaborative enterprise systems based on organization models. Science of Computer Programming, 66, 44-59.

Hernández, J.E., Mula, J. and Ferriols, F.J., 2008. A reference model for conceptual modeling of production planning processes. Production Planning \& Control, 19 (8), 725-734.

Hernández, J.E. 2011a. Propuesta de una arquitectura para el soporte de la planificación de la producción colaborativa en cadenas de suministro de tipo árbol. PhD Thesis.

Hernández J.E., Poler R, Mula J. and Lario F.C., 2011b. The reverse logistic process of an automobile supply chain network supported by a collaborative decision making model. Group Decision and Negotiation Journal 20 (1), 79-114.

Hernández, J.E., Mula, J., Poler, R. and Lyons, A.C. 2013. Collaborative planning in multi-tier supply chains supported by a negotiation-based mechanism and multi-agent system. Group Decision and Negotiation Journal. DOI: 10.1007/s10726-013-9358-2.

Hoberman, S. 2009, Data modeling made simple. Technics publications, 2nd edition, LLC 2009.

Jardim-Goncalves, R., Agostinho, C., Lamphataki, F., Chalarabidis, Y. and Grilo, A. 2013. Systematisation of Interoperability Body of Knowledge: The foundation for EI as a science. Enterprise Information Systems Journal, 7(1), 7-32.

Kampstra, R.P., Ashayeri, J., and Gattorna, J., 2006. Realities of supply chain collaboration. International Journal of Logistics Management, 17 (3), 312-330.

Kim, W., Chung, M.J., Qureshi, K. and Choi, Y.K., 2006. WSCPC: An architecture using semantic web services for collaborative product commerce. Computers in Industry, 57, 787-796.

Kua, K.C, Kaob, H.P. and Gurumurthyc, H.K., 2007. Virtual inter-firm collaborative Framework-An IC foundry merger/acquisition project. Technovation, 27, 388-401.

Lee, J., Gruninger, M., Jin, Y., Malone, T., Tate, A., Yost, G. and other members of the PIF Working Group, 1998. The process interchange format and framework. The Knowledge Engineering Review, 13 (1), 91-120.

Lee, J., Chae, H., Kim, C.H and Kim, K., 2009. Design of product ontology architecture for collaborative enterprises. Expert Systems with Applications, 36, 2300-2309.

Liu, J., Zhang, S. and Hu, J., 2005. A case study of an inter-enterprise workflow-supported supply chain management system. Information \& Management, 42, 441-454. 
Marques, D.M.N. and Guerrini, F.M., 2012. Reference model for implementing an MRP system in a highly diverse component and seasonal lean production environment. Production Planning and Control, 23 (8), 609-623.

Moutaoukil, A., Derrouiche, D. and Neubert, D. 2012. Pooling Supply Chain: Literature Review of Collaborative Strategies. IFIP International Federation for Information Processing 2012. L.M. Camarinha-Matos, L. Xu, and H. Afsarmanesh (Eds.): PRO-VE 2012, IFIP AICT 380, pp. 513-525.

Mula, J., Peidro, D. and Poler, R., 2010. The effectiveness of a fuzzy mathematical programming approach for supply chain production planning with fuzzy demand. International Journal of Production Economics, 128, 136-143.

Murata T., 1989. Petri nets: properties, analysis, and applications. Proceedings of IEEE, 77 (4), 541-580.

Murdoch, J., and McDermid, J.A., 2000. Modelling engineering design processes with role activity diagrams. Journal of Integrated Design and Process Science, 4 (2), 45-65.

NATO, 2007. Nato architecture framework. Version 3. Available at: http://www.nhqc3s.nato.int/ARCHITECTURE/_docs/NAF_v3/ANNEX1.pdf (Accessed on 02/01/2013).

Naujok, K.D. and Huemer, C., 2008. Case study: Designing ebXML- The Work of UN/CEFACT. In: Ontologies-Based Business Integration. Ed. Springer, pp. 79-93.

Noran, O., 2003. An analysis of the Zachman Framework for enterprise architecture from the GERAM perspective. Annual Reviews in Control, 27, 163-183.

Noordin, N.A., Bititci, U.S. and Van Der Meer, R. 2012. Review on Collaborative Decision Making in Supply Chain: The Relationship between E-Collaboration Technology and Development of Inter-organizational Trust. IFIP International Federation for Information Processing 2012. J. Frick and B. Laugen (Eds.): APMS 2011, IFIP AICT 384, pp. 326-341, 2012.

OASIS, 2007. Web services business process execution language version 2.0 primer. Available at: http://docs.oasis-open.org/wsbpel/2.0/Primer/wsbpel-v2.0-Primer.pdf (Accessed on 26/01/2013).

Olorunniwo, F.O. and Li, X., 2010. Information sharing and collaboration practices in reverse logistics. Supply Chain Management: An International Journal, 15 (6), 454 - 462

OMG, 2008a. Business process definition metamodel Volume I: Common infrastructure. OMG Document Number: formal/2008-11-03.

OMG, 2008b. Business process definition metamodel Volume II: Process definitions. OMG Document Number: formal/2008-11-04.

OMG, 2011. Business process model and notation v2.0. OMG Document Number: formal/2011-01-03.

Ould, M.A., 1995. Business Processes: Modelling and analysis for re-engineering and improvement, Wiley.

Peristeras, V. and Tarabanis, K., 2000. Towards an enterprise architecture for public administration using a top-down approach. Available at: http://is2.lse.ac.uk/asp/aspecis/20000162.pdf (Accessed on 30/01/2013)

Recker, J., Indulska, M., Rosemann, M. and Green, P. 2009. Business Process Modeling - A Comparative Analysis. Journal of the Association for Information Systems, vol. 10 No 4, pp. 333-363. 
Rodriguez, K., and Al-Ashaab, A., 2005. Knowledge web-based system architecture for collaborative product development. Computers in Industry, 56, 125-140.

Romero, F., Company, P., Agost, M.J. and Vila, C., 2008. Activity modelling in a collaborative ceramic tile design chain: an enhanced IDEF0 approach. Research in Engineering Design, 19, 1-20.

Sandberg, E. 2007. Logistics collaboration in supply chains: practice vs. theory. International Journal of Logistics Management, 18 (2), 274-93.

Schekkerman, 2004. Extended Enterprise Architecture Framework (E2AF). Essentials guide. IFEAD. Available at: http://www.enterprisearchitecture.info/Images/E2AF/E2AF\%20Essentials\%20Guide\%20\%20Description\%20 v48.pdf (Accessed on 26/01/2013).

Scott, K., 2001. UML Explained. Addison-Wesley Professional.

Simatupang, T.M., Sridharan, R., 2005. An integrative framework for supply chain collaboration. The International Journal of Logistics Managements, 16 (2), 254-274.

Spekman, R.E. and Carraway, R., 2006. Making the transition to collaborative buyer-seller relationships: An emerging framework. Industrial Marketing Management, 35, 10 - 19.

Stevens, W. P., Myers, G. J. and Constantine, L.L. 1974. Structured design. IBM Systems Journal, 13 (2), 115-139.

The Open Group, 2009. TOGAF v9 Enterprise Edition. Reference Q091. Available at: https://www2.opengroup.org/ogsys/catalog/q091 (Accessed on 26/01/2013).

The Supply chain Council, 2013. SCOR. Available at: http://supply-chain.org/scor (Accessed on $26 / 01 / 2013$ )

Ulieru, M., Norrie, D., Kremer, R. and Shen, W., 2000. A multi-resolution collaborative architecture for web-centric global manufacturing. Information Sciences, 127, 3-21.

van der Aalst, W., 1999. Formalization and verification of event-driven process chains. Information and Software Technology, 41 (10), 639-650.

Vries, M., van Rensburg A.J.C., 2008, Enterprise architecture - new business value perspectives. South African Journal of Industrial Engineering, 19 (1), 1-16.

W3C, 2008. XML 1.0 Specification. Available at: http://www.w3.org/TR/2008/REC-xml20081126/ (Accessed on 26/01/2013).

Zachman, J.A., 1987. A framework for information systems architecture. IBM Systems Journal, 26 (3), 276-292.

Zachman, J.A., 1997. Enterprise architecture: The issue of the century. Database Programming and Design, 10, 44-53.

Zeng, Y, Wang, L, Deng, X, Cao, X and Khundker, N., 2012. Secure collaboration in global design and supply chain environment: Problem analysis and literature review. Computers in Industry, 63, 545-556. 